\title{
Polystyrene/Clay Nanocomposites by Atom Transfer Radical Nitroxide Coupling Chemistry ${ }^{\dagger}$
}

\author{
Muhammed Aydin, ${ }^{1}$ Mehmet Atilla Tasdelen, ${ }^{2}$ Tamer Uyar, ${ }^{3}$ Steffen Jockusch, ${ }^{4}$ \\ Nicholas J. Turro, ${ }^{4, \ddagger}$ Yusuf Yagci ${ }^{1,5}$ \\ ${ }^{1}$ Department of Chemistry, Faculty of Science and Letters, Istanbul Technical University, Maslak, TR-34469 Istanbul, Turkey \\ ${ }^{2}$ Department of Polymer Engineering, Faculty of Engineering, Yalova University, TR-77100 Yalova, Turkey \\ ${ }^{3}$ UNAM-Institute of Materials Science and Nanotechnology, Bilkent University, 06800 Ankara, Turkey \\ ${ }^{4}$ Department of Chemistry, Columbia University, New York 10027 \\ ${ }^{5}$ Department of Chemistry, Faculty of Science, King Abdulaziz University, Jeddah, Saudi Arabia \\ ${ }^{\ddagger}$ Deceased. \\ Correspondence to: Y. Yagci (E-mail: yusuf@itu.edu.tr)
}

Received 4 October 2012; accepted 18 November 2012; published online 18 December 2012

DOI: $10.1002 /$ pola.26493

KEYWORDS: atom transfer radical nitroxide coupling; atom transfer radical polymerization; nanocomposites; organoclay; thermal properties

During the last two decades, the introduction of welldispersed clay layers such as montmorillonite (MMT) into a polymer matrix has been proved to be extremely effective in the improvement of mechanical, thermal, and barrier properties of the polymers. ${ }^{1}$ However, the dispersion of clay as individual platelets throughout the polymer is difficult to achieve due to strong van der Waals forces holding platelets together in conjunction with the incompatibility of the hydrophilic clay with the organophilic (hydrophobic) polymer matrix, giving way to clay agglomeration. Thus, the surface of the clays is commonly modified with a cation exchange technique to expand basal spacing and make the layered silicate compatible with polymer matrixes. Currently polymer/clay nanocomposites can be prepared by three ways such as solution mixing, melt blending, and in situ polymerization. ${ }^{2}$ In the solution mixing method, the polymer is dissolved in an organic solvent, then the clay is dispersed in the obtained solution, and subsequently, either the solvent is evaporated or the polymer precipitated. However, the large quantities of volatile solvent necessary for this approach make it less attractive as an industrial process. Melt blending is a solvent-free method to enable mixing of the layered silicate with the polymer matrix in the molten state. However, very careful attention has to be paid to finely tune the processing conditions to increase the compatibility of clay layer surfaces with the polymer matrix. ${ }^{3}$ In the in situ polymerization technique, the monomer, together with the initiator and/or catalyst, is intercalated within the silicate layers and the polymerization is initiated by external stimulation such as thermal, photochemical, or chemical activation. ${ }^{4-16}$ The chain growth in the clay galleries triggers the clay exfoliation and, hence, the nanocomposite formation.

Recently, our group has established a highly efficient method, namely, copper (I) catalyzed azide/alkyne cycloaddition (CuAAC) "click" reaction, ${ }^{17}$ in which exfoliation is rooted in the functional groups of the intercalant that readily react with the antagonist groups of the preformed polymers. ${ }^{18-20}$ To take advantage of click chemistry, azide and alkyne partners could each be incorporated in either the clay surface or polymer chain. The quantitative efficiency of coupling reaction coupled with tolerance to a wide variety of functional groups and reaction conditions make this coupling process highly attractive for the nanocomposite preparation. However, there are only few examples in the literature to date regarding the preparation of polymer/clay nanocomposites via the CuAAC click reaction. ${ }^{21-23}$

Recently, Huang and coworkers presented a rapid, selective, and reversible atom transfer nitroxide radical coupling (ATNRC) reaction, which has the attributes of a "click" reaction with quantitative yields and high tolerance of functional groups. ${ }^{24-28}$ This reaction involves formation of a reactive radical by an atom transfer reaction with a copper catalyst and trapping of this radical with a persistent nitroxide radical at close to diffusion-controlled rates. Although, this strategy has been applied for the preparation of graphene-based

${ }^{\dagger}$ This manuscript is dedicated to Nicholas J. Turro, who passed away on November 24, 2012, while working on revision to this manuscript.

(c) 2012 Wiley Periodicals, Inc. 

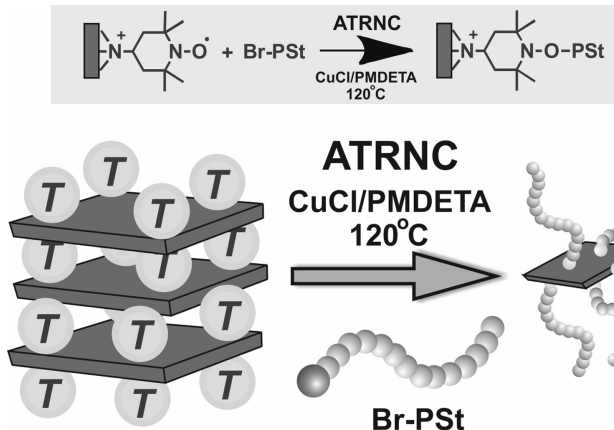

T-MMT
ATRNC CUCI/PMDETA $120^{\circ} \mathrm{C}$

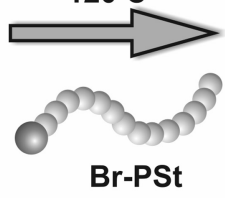

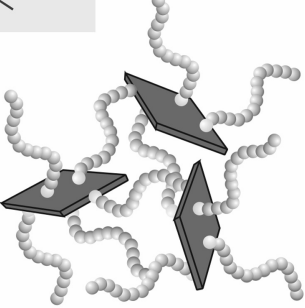

PSt/MMT Nanocomposite

SCHEME 1 Preparation of PSt/MMT nanocomposites by ATRNC chemistry.

nanocomposites, ${ }^{29}$ to the best of our knowledge, it has not been reported for polymer/clay nanocomposites in the literature. Here, we report the synthesis of polystyrene (PSt)/MMT nanocomposites by ATRNC chemistry (Scheme 1). This approach is conceived to greatly extend the synthetic capabilities of polymer/clay nanocomposites by careful choices of organic clays and polymers, and the optimization of the synthesizing process to deliver the biggest benefit.

The highly efficient ATNRC chemistry is based on mixing a nitroxide-containing molecule with corresponding halide-containing polymer in the presence of $\mathrm{CuCl} / N, N, N^{\prime}, N^{\prime \prime}, N^{\prime \prime}$-pentamethyl diethylenetriamine (PMDETA) catalytic system. It can serve as a relative convenient and safe way with "clicklike" efficiency to synthesize certain macromolecular structures with well-defined properties. For this purpose, a quaternized ammonium-containing TEMPO was first synthesized from 4-dimethylamino-TEMPO and methyl bromide, ${ }^{30}$ then ion-exchanged with sodium montmorillonite (Na-MMT) to obtain TEMPO containing organomodified clay (T-MMT). Gallery distances (basal space, $d_{001}$ ) of pure clay and organomodified-clay (Na-MMT and T-MMT) were determined by X-ray diffraction (XRD) analysis (Fig. 1 and Table 1). The pristine clay sample (Na-MMT) exhibited a peak at $9.80^{\circ}$ (Fig. 1, bottom), which corresponded to $d_{001}$ of $0.90 \mathrm{~nm}$ and this peak shifted to $7.82^{\circ}$ for T-MMT, which corresponded to $d_{001}$ of $1.12 \mathrm{~nm}$. This change indicated that TEMPO was successfully intercalated into the silicate galleries of the MMT clay. The mass loss of T-MMT was $21.4 \%$; it indicated that the percent of attached TEMPO was 13\% (Table 1). Larger interlayer spaces not only help the diffusion of polymer chains but also assist the exfoliation of silicate layers by providing more hydrophobic environment. The bromide-functionalized PSt (PSt-Br) was synthesized by typical ATRP using ethyl-2-bromopropionate as initiator and $\mathrm{CuCl} / \mathrm{PMDETA}$ as catalyst. The low-conversion (21\%) and low-molecular-weight polymer $\left(M_{\mathrm{n}}=2300, M_{\mathrm{w}} / M_{\mathrm{n}}=1.12\right)$ was prepared in order to perform successful coupling process.

A series of PSt/MMT nanocomposites (NC-1, NC-3, and NC5) were prepared by ATNRC reaction between PSt-Br and TMMT in the presence of $\mathrm{CuCl} /$ PMDETA using toluene as solvent at $90{ }^{\circ} \mathrm{C}$ and the results were summarized in Table 1.

The coupling efficiencies of ATNRC were higher than 90\%, which is similar to that of click chemistry.

Figure 1 shows the XRD patterns of PSt/MMT nanocomposites with the MMT contents of PSt-MMT- $1 \%,-3 \%,-5 \%$, and pure T-MMT. The characteristic peak of the T-MMT disappears in the XRD patterns of PSt-MMT-1\% nanocomposite (NC-1), which indicates the formation of exfoliated structure of clay. However, it was found that partially exfoliated or intercalated structures existed in the high clay content system (PSt-MMT-3\% and -5\%) probably due to the difficulty for overcoming the intensive ionic attraction between the neighboring platelets.

Although XRD offers a convenient and practical method to determine the interlayer spacing, it cannot be used alone as a criterion for exfoliation. Several factors such as clay dilution, peak broadening, and preferred orientation make XRD characterization of nanocomposite susceptible to errors. Thus, transmission electron microscope (TEM) studies are necessary to verify the dispersion of silicate layers in the polymer matrix and exfoliation achieved. Figure 2 presents the high magnification TEM images of PSt/MMT nanocomposites containing 1.0 and $5.0 \mathrm{wt} \%$ T-MMT, respectively. The dark lines represent the clay nanolayers, whereas the gray areas correspond to the PSt matrix. The images clearly revealed that some of silicate layers were dispersed uniformly, indicating most of the silicate layers were exfoliated. In some areas, intercalated layers with a size of 50-100 nm were also observed. Combined together with the results of XRD and TEM, it can be concluded that an exfoliated and intercalated structure co-exists (also called incomplete exfoliation) in the nanocomposites.

The thermogravimetric analysis (TGA) curves of pure polymer and PSt/MMT nanocomposite recorded in inert atmosphere are shown in Figure 3. As indicated in the figure, the thermal behavior of the nanocomposite is quite similar to the pure polymer and single step decomposition is observed for all the samples. The values of onset $\left(T_{10}\right)$ and midpoint $\left(T_{50}\right)$

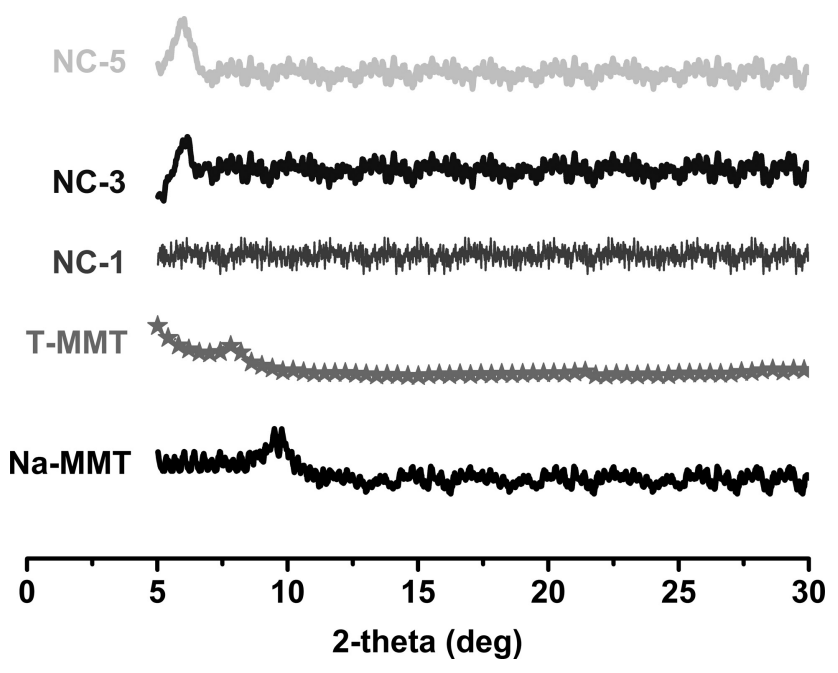

FIGURE 1 X-ray diffractions of Na-MMT, T-MMT, and all nanocomposites. 
TABLE 1 Physical Properties of PSt/MMT Nanocomposites and Their Components for Comparison

\begin{tabular}{|c|c|c|c|c|c|c|c|}
\hline \multirow[b]{2}{*}{ Entry } & \multirow[b]{2}{*}{ Clay (\%) } & \multirow[b]{2}{*}{ Conv. ${ }^{a}$} & \multirow[b]{2}{*}{$d_{001}{ }^{\mathrm{b}}(\mathrm{nm})$} & \multirow[b]{2}{*}{$T_{\mathrm{g}}{ }^{\mathrm{c}}\left({ }^{\circ} \mathrm{C}\right)$} & \multicolumn{2}{|c|}{$\begin{array}{l}\text { Weight Loss } \\
\text { Temperature } \\
\left({ }^{\circ} \mathrm{C}\right)\end{array}$} & \multirow[b]{2}{*}{ Char Yield $^{\mathrm{c}}(\%)$} \\
\hline & & & & & $10 \%$ & $50 \%$ & \\
\hline Na-MMT & - & - & 0.90 & - & - & - & 91.6 \\
\hline T-MMT & - & - & 1.12 & - & 498 & - & 78.6 \\
\hline PSt-Br & - & - & - & 93 & 290 & 348 & $<1$ \\
\hline $\mathrm{NC}-1$ & 1 & 91 & - & 96 & 292 & 385 & 8.2 \\
\hline $\mathrm{NC}-3$ & 3 & 93 & 1.43 & 101 & 304 & 393 & 11.9 \\
\hline NC-5 & 5 & 96 & 1.50 & 105 & 343 & 400 & 14.1 \\
\hline
\end{tabular}

degradation temperatures are compared in Table 1. It can be clearly found that both degradation temperatures of the nanocomposites shifted significantly toward higher temperatures compared with those of the neat PSt. These improvements could be associated with the clay as an inorganic material with high thermal stability and great barrier properties that can prevent the heat from transmitting quickly and can limit the continuous decomposition. As the clay contents increases from 1 to 5 wt \%, the increase of $8.2-14.1 \%$ of the char residue is also observed, which means that the silicate layers can promote the charring process during the decomposition process. The increase in char yield implies the reduction of the polymer's flammability. According to the differential scanning calorimetry (DSC) characterization, the glass transition temperature of the nanocomposites increased with the clay content by a maximum of $12^{\circ} \mathrm{C}$ (Table 1$)$.

In summary, the ATRNC chemistry has been extensively used for past years in synthesis of various complex macromolecular architectures. Applied to polymer/clay nanocomposites, this reaction demonstrated its potential and versatility.
Spectroscopic and microscopic investigations revealed that successful nanocomposite formation has been achieved by this method. Addition of small amounts of layered silicate loadings resulted in remarkable improvements of thermal properties of nanocomposites. The ATRNC chemistry may be an ideal modular methodology for the introduction of a wide variety of molecules in to clay layers. By applying this approach, one can easily prepare polymer nanocomposites with desired properties, which enhance their importance in material science.

\section{EXPERIMENTAL}

\section{Materials}

Na-MMT (Cloisite $\mathrm{Na}^{+}$) was purchased from Southern Clay products with cation exchange capacity of 92.6 mequiv/100 $\mathrm{g}$ and used as received. Styrene (St, 99\%, Aldrich) was passed through a basic alumina column to remove the inhibitor. PMDETA (99\%, Aldrich), as a ligand, was distilled before use. Ethyl-2-bromopropionate (99\%, Aldrich) and copper(I) chloride (97\%, Aldrich) were used as received. Quaternary
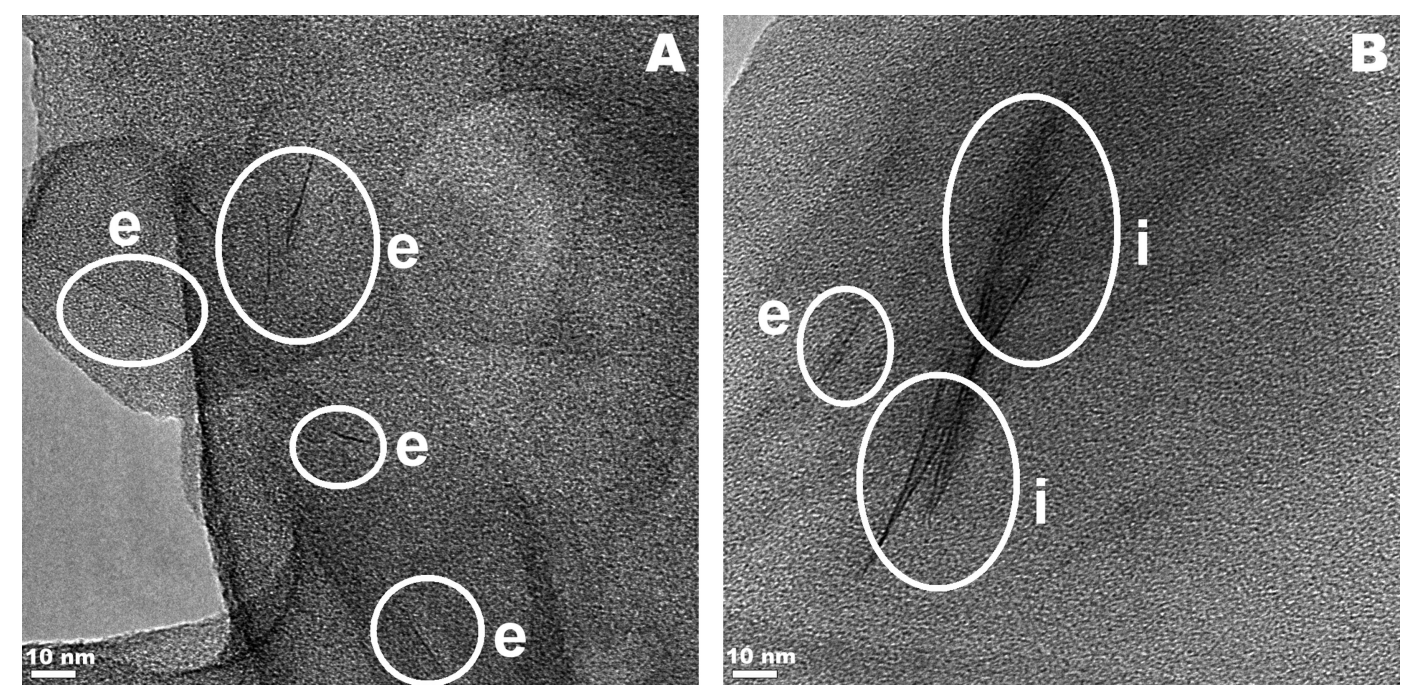

FIGURE 2 TEM micrographs showing exfoliated/intercalated silicate layers in NC-1 (A) and NC-5 (B) samples at $10 \mathrm{~nm}$ magnifications. 


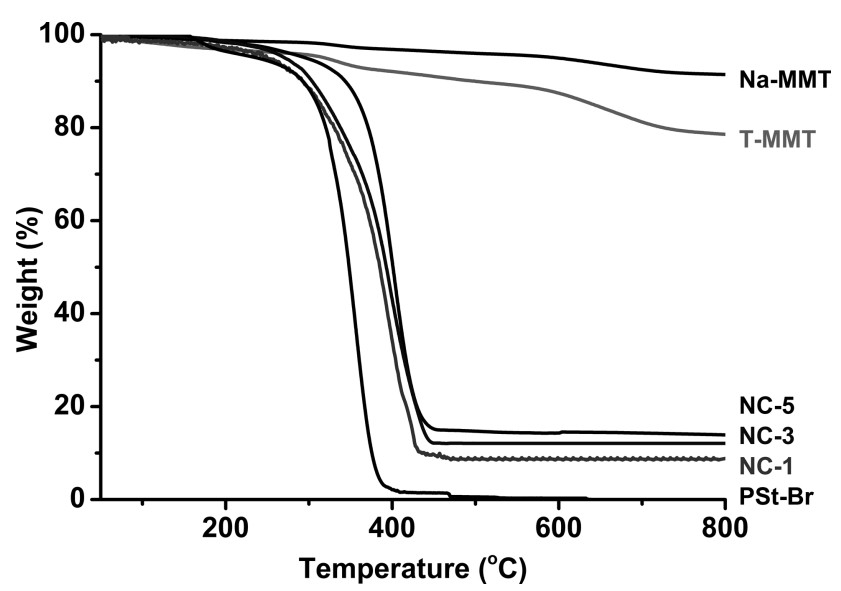

FIGURE 3 TGA thermograms of Na-MMT, T-MMT, PSt-Br, and PSt/MMT nanocomposites.

ammonium-2,2,6,6-tetramethyl-1-piperidinyloxy (Q-TEMPO) synthesized according to the literature procedure. ${ }^{30}$ Other solvents were purified by conventional drying and distillation procedures.

\section{Preparation of Organically Modified Clay (T-MMT)}

The organically TEMPO-modified montmorillonite (T-MMT) was prepared through cationic exchange between Na-MMT and Q-TEMPO in an aqueous solution. A separate solution of MMT (50 mg) and Q-TEMPO (20 mg, $0.1 \mathrm{mmol}$ ) was dispersed in $10 \mathrm{~mL}$ of deionized water at $50{ }^{\circ} \mathrm{C}$ for $24 \mathrm{~h}$. Then, the two solutions were mixed vigorously and the total volume was brought up to $100 \mathrm{~mL}$ and stirred for $24 \mathrm{~h}$ at 50 ${ }^{\circ} \mathrm{C}$. After mixing, the T-MMT was recovered by filtering the solution, followed by repeated washings of the filter cake with deionized water to remove the excess of ions. The final product was dried in a vacuum oven at room temperature for $24 \mathrm{~h}$.

\section{Preparation of Polystyrene by ATRP (PSt-Br)}

$\mathrm{CuCl}(0.25 \mathrm{~g}, 1.72 \mathrm{mmol})$, PMDETA (361 $\mu \mathrm{L}, 1.72 \mathrm{mmol})$, ethyl-2-bromopropionate as an initiator (225 $\mu \mathrm{L}, 1.72 \mathrm{mmol})$, and styrene $(20 \mathrm{~mL}, 172 \mathrm{mmol})$ were introduced in a Schlenk tube, and the reaction mixture was degassed by three freezepump-thaw cycles and sealed in vacuum. The tube was heated to $90{ }^{\circ} \mathrm{C}$ in an oil bath and stirred for $45 \mathrm{~min}$. Then, the mixture was diluted with THF, and passed through an alumina column to remove the complex salts. Precipitation of the polymer was performed in a 10 -fold volume of methanol. The solid was then collected after filtration. (Conversion = $12, M_{\mathrm{n} \text {, theo }}=2520, M_{\mathrm{n}, \mathrm{GPC}}=2300, M_{\mathrm{w}} / M_{\mathrm{n}}=1.12$ ).

Synthesis of Polystyrene/MMT Nanocomposites (NC-1, NC-3, and NC-5) via ATRNC Chemistry

The organophilic clay (T-MMT, $1 \%, 3 \%$, and $5 \%$ of the monomer by weight), PSt-Br (230 mg, $0.1 \mathrm{mmol}$ ), PMDETA (60.3 $\mu \mathrm{L}, 0.3 \mathrm{mmol}$ ), copper chloride ( $\mathrm{CuCl}, 9.9 \mathrm{mg}, 0.1 \mathrm{mmol})$, and toluene (1 $\mathrm{mL}$ as solvent) were mixed into a round-bottom flask, and then, the reaction mixture was degassed by three freeze-pump-thaw cycles and sealed in vacuum. The mixture was placed in a thermostated oil bath at $120{ }^{\circ} \mathrm{C}$ for $4 \mathrm{~h}$. At the end of the polymerization, the mixture was precipitated into methanol, filtered, dried, and weighted.

\section{Characterization}

Molecular weights were determined by gel permeation chromatography (GPC) using an instrument consisting of a Viscotek GPCmax Autosampler, a pump, three ViscoGEL GPC columns $\left(\mathrm{G} 2000 \mathrm{H}_{\mathrm{HR}}, \mathrm{G} 3000 \mathrm{H}_{\mathrm{HR}}\right.$, and $\left.\mathrm{G} 4000 \mathrm{H}_{\mathrm{HR}}\right)$, and a Viscotek differential refractive index (RI) detector with a THF flow rate of $1.0 \mathrm{~mL} \mathrm{~min}^{-1}$ at $30{ }^{\circ} \mathrm{C}$. The RI detector was calibrated with PSt standards having narrow molecular weight distribution. Data were analyzed using Viscotek OmniSEC Omni-01 software. The powder XRD measurements were performed on a PANalytical X'Pert PRO X-ray diffractometer equipped with graphite-monochromatized $\mathrm{Cu} \mathrm{K} \alpha$ radiation $(\lambda=1.15 \AA)$. DSC was performed on a PerkinElmer Diamond DSC with a heating rate of $20{ }^{\circ} \mathrm{C} / \mathrm{min}$ under nitrogen flow $(20 \mathrm{~mL} / \mathrm{min})$. TGA was performed on a Perkin-Elmer Diamond TA/TGA with a heating rate of $10{ }^{\circ} \mathrm{C} /$ min under nitrogen flow (200 $\mathrm{mL} / \mathrm{min})$. TEM imaging of the samples was carried out on a FEI Tecnai ${ }^{\mathrm{TM}} \mathrm{G}^{2}$ F30 instrument operating at an acceleration voltage of $200 \mathrm{kV}$. Ultrathin TEM specimens (ca. $100 \mathrm{~nm}$ ) were prepared by using a cryo-ultramicrotome EMUC $_{6}+\mathrm{EMFC}_{6}$, Leica) equipped with a diamond knife. The ultrathin samples were placed on holey carbon-coated grids for TEM analyses.

\section{ACKNOWLEDGMENTS}

M. Aydin and Y. Yagci thank Istanbul Technical University, Research Fund for financial support. N. J. Turro and S. Jockusch thank the National Science Foundation, USA for financial support through grant NSF-CHE-11-11398.

\section{REFERENCES AND NOTES}

1 M. Alexandre, P. Dubois, Mater. Sci. Eng. R 2000, 28, 1-63. 2 S. S. Ray, M. Okamoto, Prog. Polym. Sci. 2003, 28, 1539-1641. 3 S. Pavlidou, C. D. Papaspyrides, Prog. Polym. Sci. 2008, 33, 1119-1198.

4 M. A. Tasdelen, J. Kreutzer, Y. Yagci, Macromol. Chem. Phys. 2010, 211, 279-285.

5 H. Akat, M. A. Tasdelen, F. Du Prez, Y. Yagci, Eur. Polym. J. 2008, 44, 1949-1954.

6 A. Oral, M. A. Tasdelen, A. L. Demirel, Y. Yagci, J. Polym. Sci. Part A: Polym. Chem. 2009, 47, 5328-5335.

7 Z. Yenice, M. A. Tasdelen, A. Oral, C. Guler, Y. Yagci, J. Polym. Sci. Part A: Polym. Chem. 2009, 47, 2190-2197.

8 O. Eksik, M. A. Tasdelen, A. T. Erciyes, Y. Yagci, Compos. Interfaces 2010, 17, 357-369.

9 C. Altinkok, T. Uyar, M. A. Tasdelen, Y. Yagci, J. Polym. Sci. Part A: Polym. Chem. 2011, 49, 3658-3663.

10 K. D. Demir, M. A. Tasdelen, T. Uyar, A. W. Kawaguchi, A. Sudo, T. Endo, Y. Yagci, J. Polym. Sci. Part A: Polym. Chem. 2011, 49, 4213-4220.

11 C. Dizman, S. Ates, T. Uyar, M. A. Tasdelen, L. Torun, Y. Yagci, Macromol. Mater. Eng. 2011, 296, 1101-1106.

12 A. Nese, S. Sen, M. A. Tasdelen, N. Nugay, Y. Yagci, Macromol. Chem. Phys. 2006, 207, 820-826.

13 M. Huskic, E. Zagar, M. Zigon, Eur. Polym. J. 2012, 48, $1555-1560$. 
14 M. Huskic, M. Zigon, Eur. Polym. J. 2007, 43, 4891-4897.

15 H. Datta, A. K. Bhowmick, N. K. Singha, J. Polym. Sci. Part A: Polym. Chem. 2008, 46, 5014-5027.

16 D. J. Haloi, N. K. Singha, J. Polym. Sci. Part A: Polym. Chem. 2011, 49, 1564-1571.

17 H. C. Kolb, M. G. Finn, K. B. Sharpless, Angew. Chem. Int. Ed. Engl. 2001, 40, 2004-2021.

18 M. A. Tasdelen, W. Van Camp, E. Goethals, P. Dubois, F. Du Prez, Y. Yagci, Macromolecules 2008, 41, 6035-6040.

19 A. Oral, M. A. Tasdelen, A. L. Demirel, Y. Yagci, Polymer 2009, 50, 3905-3910.

20 M. A. Tasdelen, Eur. Polym. J. 2011, 47, 937-941.

21 Y. S. Ye, Y. C. Yen, C. C. Cheng, Y. J. Syu, Y. J. Huang, F. C. Chang, Polymer 2010, 51, 430-436.

22 J. C. Chen, H. D. Wang, W. Q. Luo, J. M. Xiang, L. H. Zhang, B. B. Sun, Colloid. Polym. Sci. 2010, 288, 173-179.
23 J. C. Chen, J. M. Xiang, Z. W. Cai, H. Yong, H. D. Wang, L. H. Zhang, W. O. Luo, H. Min, J. Macromol. Sci. Pure Appl. Chem. 2010, 47, 655-662.

24 Q. Fu, W. Lin, J. Huang, Macromolecules 2008, 41, 2381-2387.

25 Q. Fu, C. Liu, W. Lin, J. Huang, J. Polym. Sci. Part A: Polym. Chem. 2008, 46, 6770-6779.

26 C. Liu, M. Pan, Y. Zhang, J. Huang, J. Polym. Sci. Part A: Polym. Chem. 2008, 46, 6754-6761.

27 Q. Fu, G. Wang, W. Lin, J. Huang, J. Polym. Sci. Part A: Polym. Chem. 2009, 47, 986-990.

28 Q. Fu, G. W. Wang, W. C. Lin, J. L. Huang, J. Polym. Sci. Part A: Polym. Chem. 2009, 47, 986-990.

29 Y. Deng, Y. Li, J. Dai, M. Lang, X. Huang, J. Polym. Sci. Part A: Polym. Chem. 2011, 49, 1582-1590.

30 S. Jockusch, O. Zeika, N. Jayaraj, V. Ramamurthy, N. J. Turro, J. Phys. Chem. Lett. 2010, 1, 2628-2632. 